DOI: $10.7596 /$ taksad.vli1.6

\title{
Antik Yakın Doğu Milletlerinde Tanrı
}

Mustafa Yiğitoğlu: Karabuk University, Turkey.

\section{Özet:}

$\mathrm{Bu}$ çalışma antik dönem yakındoğu literatüründe tanrı kavramını incelemektedir. $\mathrm{Bu}$ konu, o dönemde yaşamış milletlerin tanrı hakkındaki düşüncelerini kavrayabilmemiz açısından oldukça önemlidir. Zira ele aldığımız bu dönem tanrı düşüncesi açısından merak edilen bir dönemdir. Bunun nedeni ise, elde edilebilen ilk dökümanların bu döneme ait olan dökümanlar olmasıdır.

Anahtar Kelimeler: Antik Yakın Doğu, Tanrı, Sümer, Akat, Babil, Hitit, Mısır

\section{The Conception Of God In The Ancient Near Eastern Literature}

\section{Abstract:}

This study examines the notion of God in the ancient near eastern literature. Exactly this subject is very important to conceive of the ancient near eastern people's God conception. Forasmuch as this era is concerned about ancient people's opinion of God. Because the first documents could be obtained about the conception of god are the documents about the ancient near eastern societies.

Key Words: Ancient Near East, God, Sumerian, Akkadian, Babylon, Hittite, Egyptian, Literature

\section{Le Concept de Dieu dans les Nations du“Proche-Orient Antique}

\section{Résumé}

Cette étude examine le concept de dieu dans la littérature du Proche-Orient de la période antique. Ce sujet est très important pour comprendre les pensées des gens vécus dans cette période de l'histoire au sujet de dieu. Car cette période est celle qui mérite d'être examiné du point de vue de la pensée de dieu parce que les premiers documents qu'on possède à ce propos appartiennent à cette période.

Mots-Clés: Proche-Orient Antique, Dieu, Sumer, Akkad, Babylone, Hittite, Egypte. 


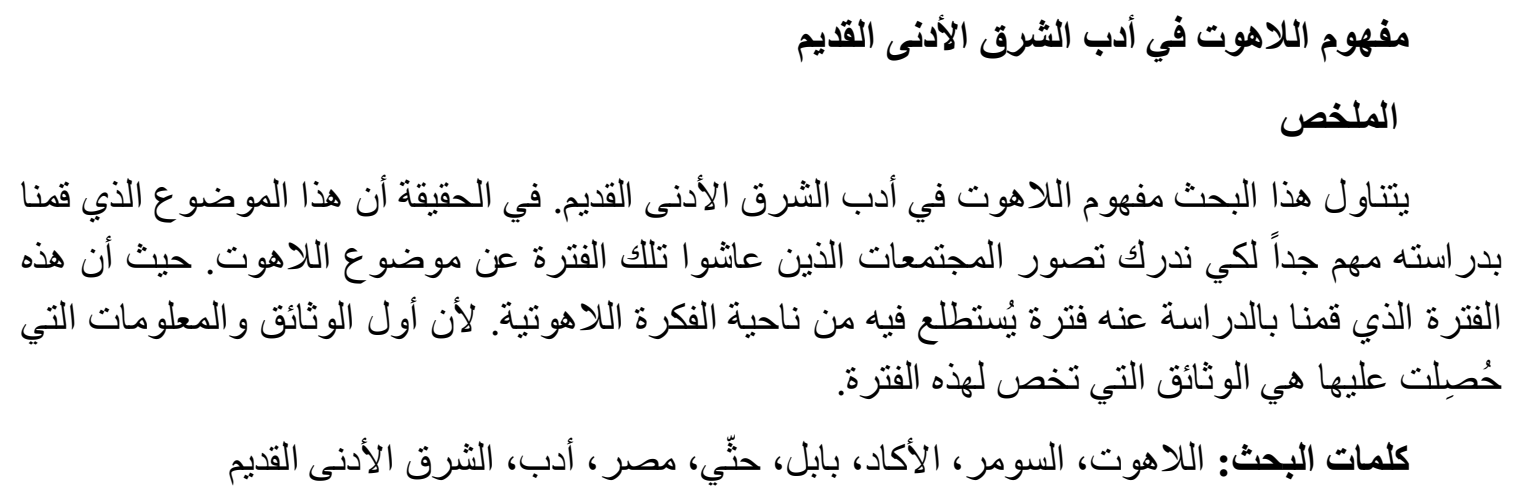

\section{GíRiș}

Çalışmamızın konusu antik yakın doğu milletlerinden Sümer, Akat, Babil, Hitit ve Mısırlılarda Tanrı mefhumudur. Antik dönemde yaşamış büyük devletlerin halklarının zihinlerinde ne tür bir Tanrı mefhumu bulunduğu ve ona ne surette değer atfettikleri merak konusudur. Antik Yakın Doğu toplumlarında Tanrı'nın oldukça önemli bir yere sahip olduğunu söyleyebiliriz. Bu durum, birçok araştırmacı tarafından da teyit edilmektedir. Lakin, incelediğimiz konu hakkında çok detaylı bir inceleme de yapılmış değildir. Bu gaye ile o dönemde oluşturulduğu bilinen metinlere ağırlık verilerek antik dönemin büyük milletlerinin Tanrı fikriyatı gözden geçirilecektir. Zira elde ettiğimiz sonuçlar araştırmamıza, zikrettiğimiz hususların anlatılmasına ve anlaşılmasına katkı sağlayacaktır.

Antik dönemde Tanrı'ya dair ilk delil Gudea Silindirlerindeki ${ }^{1}$ Sümer Yazıtlarında görülmektedir. Bu metinlerde 'Tanrı'ya bir tapınak yapma'(The building of Ningirsu's Temple, 2006) ile ilgili bilgiler yer almaktadır. Lagaş Kralı Ningirsu' nun Tanrı' ya sunulmak üzere bir bina inşa etmesi Sümerlerde Tanrı'ya veya Tanrılara özel bir önem atfedildiğinin göstergesidir.

\section{SÜMERLERDE TANRI}

Sümerlerin yaşadığı beldelerde tanrı için yaptıkları ibadethanelerin önemli bir yer teşkil ettiği açıktır. ${ }^{2}$ Çünkü Sümerler kendilerini, inançları gereği tanrılara kurban sunmak ve mâbed yapmak için yaratıldıklarını düşünmekteydi ve bu nedenle de inandığı tanrı ya da tanrılara her zaman mâbedler inşa etmişlerdir. Sümerler yaptıkları mâbedlerde tapındıkları tanrıların heykellerini muhafaza eder ve onlara kurban kesimi yaparlard1. Bu nedenle mabette hemen hemen her bir tanrıya hizmet eden görevliler bulunurdu (Güç, 1988).

\footnotetext{
${ }^{1} \mathrm{Bu}$ silindirler, Lagaş'ta arkeolojik kazılardan sonra çıkarılan silindir şeklindeki taş üzerine yazılı 54 sütun ve 1400 satır aralığında ilahiler şeklinde, şiirsel dille yazılmış yazılardır. Bu döneme ait tek muhafaza edilmiş eser olarak günümüze kadar ulaşmıştır. Tapınak ilahileri türünde, kraliyet yazıları olan Gudea silindirleri, Lagaş kralı Gudea tarafından Ningirsu ilahı için yapılan tapınağın anısına M.Ö. yaklaşık 2125 yılında yazılmıştır. Geniş Bilgi için bkz. (Kramer, 1963a, s.137).

${ }^{2}$ Tanrıları adına yapılan tapınakların ayrıntılı bilgisi için bkz. (Kramer, 1988b, s.1-16).
} 
Sümerlerde tanrılar için oluşturulan tapınaklara verilen değer ve bu yapıların toplum yaşantısındaki merkeziyeti, antik dönemdeki bu toplumda hayatın tüm alanında Tanrı'ya verilen önemi işaret etmektedir. Elde edilen arkeolojik veriler Sümer toplumunda Tanrı'nın her alanda etkin olduğunu göstermektedir.

Sümerlere ait 'İnanna'nın Ölüler Diyarına İnişi ${ }^{3}$ adlı metinlerde tanrıya dair bilgiler mevcuttur. Buradaki metinlerde, semânın kraliçesi İnanna'nın sevgilisi Tammuz ölüm tanrıçası tarafından tutsak alınır. Bütün olumsuzluklara rağmen İnanna Tammuz'u kurtarmaya karar verir ve bunun için dönüşü mümkün olmayan ölüler diyarına gider. Ölüler diyarının tanrıçası İnanna' nın ablası olan ölüm tanrıçası Ereşkigal'dir. Ereşkigal' den kurtulmak isteyen İnanna kendi ulağına tanrılar meclisine ulaşması ve kendisi için ağıtlar yakmasını ister (Kramer, 1961d). Bu hikayede geçen diyalogtan anlaşılmaktadır ki, tanrılar arasında ciddi bir mücadele söz konusudur ve burada tanrılar adeta insanlar gibi düşünülmektedir. Ayrıca Sümerlerin su tanrısı Enki'nin yeryüzünün düzeni ve işleyişi ile ilgili yasaların oluşturulması hikâyesinde tanrı Enki' nin kral olduğu ve krallık tacı giydiğinden bahsetmektedir (Kramer, 1961d).

Metinleri incelediğimizde özetle Sümerlerde tanrı, ilahi hükümler veren, kaderi belirleyen, her türlü karar alabilen, adına kurbanlar kesilen, tapınaklar yapılan, saraylarda yaşayan, bir diğer mevkidaşı ile savaşan, yeri gelince aşı olan insan karakterlerine haiz bir kişidir.

\section{AKATLARDA TANRI}

Antik yakın doğu milletlerinden Akatlar ise genel itibariyle Sümerler ile benzer özellikleri içermektedir. Zira efsane ve hikâyelerin pek çoğu Sümerli efsanecilere dayandırılmaktadır. Konumuz açısından Gılgamış destanı (Duralı, 2007; Eyüpoğlu, 2006) önemlidir. Bu destan Akatça çivi yazısı ile on iki tablet üzerine yazılmış tarihin en eski yazılı metinlerindendir.

Gılgamış destanı tanrılara dair bilgiler vermektedir. Bu destanda tanrılar olan Anu, Enlil Ea ve semanın tanrısı Şamaş'tan bahsedilir ve bu tanrılar semada mevcut bir meclis etrafında toplanmış ve orada kararlar almaktadırlar. ${ }^{4}$ Mecliste alınan kararlar muhtemelen ölüm kararları ile ilgilidir (Kovacs, 1989, s.93). Anlatılan satırlarda Akatlarda tanrı, Sümer tanrıları gibi, gökte oluşturulmuş meclis etrafında bir araya gelen, kararlar alan, insanları ölümle cezalandıran, mükafatlar veren, tapınağında duran, taç giyen, devleti ve milleti yöneten kraldır.

\footnotetext{
${ }^{3} \mathrm{Bu}$ metin uzun süredir ‘İştar'ın Ölüler Diyarına İnişi’ olarak bilinmiş, Bâbil 'Yaratılış Destanı' gibi, bu metinler de Akatça yazılmış ve Sami Kökenli olduğu kabul edilmişti. Fakat zamanla yapılan çalışmalar neticesinde bu metinlerin Sami kökenli olmadığı ve İştar'ın Sümer karşılığı olan İnanna'nın yerini aldığı anlaşılmıştır. Ayrıntılı bilgi için bkz. (Kramer, 1944c, s.84).

${ }^{4}$ Ayrıntılı bilgi için ayrıca bkz. (Kovacs, 1989, s59).
} 


\section{BABİLLILLERDE TANRI}

Antik yakın doğu milletlerinden Babillilerin tanrı düşüncesine dair ilk ipuçları ise Hammurabi kanunlarında ${ }^{5}$ görülebilir. Bu kanunların önsözünde Hammurabi kendisini Ebabbar tapınağının kurucusu olduğunu ifade etmektedir (Roth, 1997). Hamurrabi'nin kurmuş olduğu Ebabbar tapınağı ise tanrıların yaşadığı, ilahi kararların alındığı önemli bir mekandır. Yine bu kanunların önsözündeki ifadelerden de Hammurabinin tanrılarla sıkı bir diyalog halinde olduğu anlaşılmaktadır. Kanunların önsözünde Hammurabi’ ye tanrı Inanna ve Zababa silah, Enki görme kabiliyeti, Marduk güç kudret ihsan eylemiştir. Hamurrabi bu güç kudret ile sema ve yeryüzünde düşmanlarını yenmiş tanrı Şamaş'ın emriyle de kralın adaleti memlekette tecelli etmiştir. Bu sebeple İştar'ın sevgilisi, Şamaş'ın kölesi olarak Hamurrabi Marduk'un gönlünü etmiştir. (King, 1901a).

Babil kültürüne ait Bâbil efsanesi Enuma Eliş ${ }^{6}$ te halkın tanrıya şükranlarını belirtmek maksadı ile tanrı adına Bâbil'deki tarihi Marduk mâbedi olarak tanımlanan Esagila tapınağını yaptığından bahsedilmektedir (Bratcher, 2006). Bu metinlerde Tanrı'ya karş1 minnettarlıklarını belirtmek maksadı ile kerpiç ile örülü, içerisinde Tanrı için kurulu taht, kendilerinin dinlenmesi için oturma yerleri ve yatakhanelerden müteşekkil bir mabet yapılması anlatılmaktadır (King, 1902b). Devam eden bölümlerde, yapılan bu yapı 'saray-ev' olarak nitelendirilmektedir. Metinlerde geçen 'saray' ifadesiyle, Babillerin düşüncesindeki Tanrı'nın saraylarda yaşayan bir tür kral olarak görüldügü sonucu çıkartılır. Ayrıca 'yapılan binaların hem gök hemde yer'(King, 1902b) ile irtibatlandırılması Tanrı'nın gök ile yer arasında gidip gelen bir imajının olduğunu da gösterir. Bu imaja, Sümer büyü metinleri; ‘ölüler diyarı', 'yer ve gök' olmak üzere farklı âlemlerden bahsedilmesi örnek olarak verilebilir.

Enuma Eliş’teki metinlerde tanrıya yiyeceklerden adaklar sunularak tapınaklarda buhurlar yakıldığından bahsedilmektedir. Bu metne göre, bizler o dönemde yaşayan halkların tanrıya nasıl ibadet ettiklerini, ne tür hürmet gösterdiklerini anlıyoruz. Çünkü satırlarda yiyeceklerin adak olarak sunulması ve 'buhur yakma' vb. ritüellerden bahsedilmesi konumuza 1şık tutmaktadır. Ayrıca bu ibadetlerin yapılması, buhur yakılması boşa değildir, öyle ki bu fiiliyatların gerçekleşmesi sonucu tanrı bu kişilerin evlerini şenlendirecek ve kendilerini tüm sıkıntılardan kurtaracaktır (Heidel, 1951).

Yukarıda belirttiğimiz örnekler Babil'de tanrılara çokça değer atfedildiğini göstermektedir. Zira Babil'de Tanrılara mabedler (ziggurat) ${ }^{7}$ inşa edilmekte, adına ağıtlar

\footnotetext{
${ }^{5}$ Babil Kralı Hammurabi tarafından, Bâbil'in koruyucu tanrısı Marduk adına inşa edilen tapınağa dikilen bir taş üzerine Akatça yazılan metinlerdir. Hammurabi Kanunları, takriben M.Ö. 1780 yıllarında Mezopatamya'da yaşanan tarihin iyi korunmuş yazılı belgelerdir. Hammurabi kendisine bu kanunları yazdıranın güneş tanrısı Şamaş olduğunu belirtmektedir. Ayrıntılı bilgi için bkz. (Johns, 1911).

${ }^{6}$ Yaratılış destanı diye isimlendirilen, M.Ö. 12. yüzyıl çivi yazısı ile yedi kil tablet üzerine yazılan Bâbil efsanesidir. M.S. 19. yüzyıl ortalarında Ninova'da Asur sarayının yıkıntılarında bulunmuştur. George Smith 1876' da Kildani Yaratılışı olarak bu metinleri basmıştır. Enuma Eliş’te bahsedilen konular Kutsal Kitap Yaratılış Kitabı'nın ilk iki bölümünde anlatılanlar ile paralellik arz etmektedir

${ }^{7}$ Bâbillilerde diğer bölgelerdeki bilinene nazaran 'ziggurat' adı verilen kuleler yapılmaktaydı. Bu kule mabedler kademeli olarak yükselen, tuğladan yapılardı. Kitâb-1 Mukaddes'te zikredilen Bâbil Kulesi'ne Marduk'un Bâbil'deki zîgguratı model teşkil etmiştir. Ayrıntılı bilgi için bkz. (Güç, 1988, s.277 ).
} 
yakılmakta ve kendilerine bir çok üstün vasıflar yüklenmektedir. Buna rağmen Eski Ahit'te o dönemde Babil kralı ve halkının Yahudi tanrısına karşı savaş açtığı anlatılmaktadır (Kutsal Kitap, Yar, 11/1-9). Kutsal Kitap'ta zikredilen, Bâbil hikâyesinde, kulenin yapılması o dönemin insanlarının semâya yükselerek tanrıya karşı meydan okuma amacı taşıdığını göstermektedir. ${ }^{8}$ Bir yandan tanrılara önem veren, adına tapınaklar inşa eden Babil, diğer bir yandan o dönemde tek tanrı inancını benimseyenlerin mabuduna karşı da cephe almıştı. Bu olay o dönemde tek tanrı zihniyetine karşı duruşu göstermektedir.

\section{HITITLILERDE TANRI}

Hitit kaynaklarında tanrı düşüncesine dair izler bulmak mümkündür. Hititliler tanrılarını hem gökte hemde yeryüzünde tanrılar için oluşturdukları mabedlerde görmektedir. Bunun en önemli kanıtı Ullikummi Ezgisi'nde geçmektedir (Hoffner, 1998, s.58). Burada Kumarbi ${ }^{9}$ ile Tessup ${ }^{10}$ arasında bir taht kavgası anlatılmaktadır. Kumarbi Tessub'u yenmek maksadı ile Ullikummi adındaki oğlunu ona gönderir ve Kumarbi'nin oğlu gökteki tapınaklara (karimmus) ve kuntara evine ulaşarak 'gögü, kutsal mâbedi (karimmi) ve Hebat'ı rehin alır ve Tessubu engellemeyi başarır (Hoffner, 1998, s.65).

Yukarıda anlatılan hikayede açık bir şekilde tanrılar arası mücadele söz konusudur. Çünkü hadise, kuntara-mâbedi semâda yer alan, baş tanrının kutsal mekanında geçmekte ve tanrılar arasındaki fiili çarpışmayı konu edinmektedir. Çok tanrılı bir anlayışa haiz Hititlilerde tanrılar, genellikle gökte bulunan, bazen yeryüzüne inen ve ciddi manada birbirleri ile çatışan, birinin diğerini yenebildiği bir güce sahip olan antropomorfik tiplerdir.

\section{MISIRLILARDA TANRI}

Mısır kaynaklarında tanrı düşüncesine dair pek çok ize rastlamak da mümkündür. Aşağıda sunacağımız bazı örnekler Mısırlılarda tanrı düşüncesini saptamada önem arz etmektedir. Bunların ilki Piramit metinleri, yani eski Mısır'dan günümüze ulaşabilen en eski büyülü dinsel belgeleridir. ${ }^{11}$ Bu metinlerin yazılmasındaki önem, ölü krala sunulan özel bir hizmet olmasıdır çünkü yazılanlar tanrıların bulunduğu kata yani semâya yükselir ve tanrılar arasında makbul olur. Ayrıca Piramit metinlerinde öteki âlemden bahsedilmektedir. Burada

\footnotetext{
${ }^{8}$ Beni İsrail geleneğinde var olan, o dönemin kralının (Nemrud'un) Allah'a meydan okumak ve ona saldırmak için yüksekçe bir kule yaptırması, Kur'an-1 Kerim'de de zikredilmiştir. Metne göre, Firavun: "Ey ileri gelenler! Sizin benden başka tapacak bir tanrınız olmadığına eminim. Ey Hâmân! Benim için çamur üzerine ateş yak (tuğla yap) ve bana öyle yüksek bir kule yap ki Mûsâ'nın tanrısına çıkabileyim” demiştir. (Kasas, 28/38; Mü’min, 40/36-37).

${ }^{9}$ Gökyüzü Tanrı'sının (Anu'nun) oğlu

${ }^{10}$ Tessub, yüce fırtına tanrısı ve Hurrî teolojisine göre tanrıların Hâkim kralıdır (Hoffner, 1998 s.113).

${ }^{11}$ V. hanedanı Kral Unas'tan itibaren bu metinler değişik sözleri eski krallığın kral piramitlerine, özellikle de lahid odalarına yazılmıştır. Bu yazılar, Kral Teti'nin tabutunun üzerinde yer alır ve I. Pepi' yle birlikte bunlar ön odaların dışına taşınmıştır. II. Pepi zamanında M.Ö. 2200'den sonra kraliçenin piramitlerine, eski krallığın sonundan itibaren memurların mezarlarında da kullanılmıştır. Orta krallık piramitlerinde ise bu metinlere rastlanmamakta fakat yeni krallıkta bu metinlere tekrar rastlanmaktadır. Ayrıntılı bilgi için bkz. (Homung, 2006, s. 19).
} 
bahsedilen âlemin tanımı net değildir; fakat burada cennet benzeri önemli mekânlar mevcuttur. Güneş tanrısı Horus'un kararlarını verdiği evi, gökte konuşlu cennette bulunmaktadır (Pyramid texts, 2007).

Eski Krallık Piramitlerinde ölen Mısırlılar adına genellikle papirüs üzerine yazılan, kıdemli kişilerin mezar duvarlarına işlenen bu metinler Ölüler Kitabı olarak bilinmekte ve dünyanın en eski cenaze ile ilgili belgeleri olarak kabul edilmektedir (The book of the dead, 2007). Ölüler Kitabı'nda yer alan tanrı düşüncesine dair bilgileri görmek önemlidir. Çünkü Ölüler Kitabı, incelediğimiz konu ile ilgili bilgiler vermektedir. Bir firavunun dirilişini gösteren kabartmada ölü firavunların kutsanması anlatılmaktadır. Hikayede kutsanan firavunlar Osiris'e ${ }^{12}$ rahiplerin 'Tanrıça Tefnut beni temizledi, temizliğim ellerimdedir'(Champdor, 2006, s.18) sözleri eşliğinde giderler. Burada konu edindiğimiz metinde, ahiretle ilgili bir husus yani insanların ölümden sonra tekrar hayat buluşu bunun akabinde de insanların cennete yükselişi ele alınmıştır.

Mısır kaynaklarından atıf yaptığımız metinlerden yola çıkarak antik yakın doğu milletlerinden Mısırlıların çok tanrılı bir inanca sahip olduğunu anlıyoruz. Bu metinlerde cennette ve yeryüzünde bulnan Mısır tanrıları bağışlayıcı, cezalandırıcı bir özelliğe sahiptir. Kralların mezarlarına yazılan büyülü metinlerin tanrılara karşı bir ödev olarak algılanması ve yazıldığı kişilerin bağışlanacağının belirtilmesi Mısır'da tanrılara karşı verilen önemi gösteren bir husustur.

\section{SONUÇ}

Çalışmamızda antik yakın doğu milletlerindeki (Sümer, Akat, Babil, Hitit ve Mısır) Tanrı mefhumunu inceledik. Tanrı'ya olan inanç günümüzde olduğu gibi şüphesiz geçmişte de tüm insanlığın bir ihtiyacı olmuştur. O nedenle Tarihte yaşayan ve insanlık medeniyetine çok büyük katkıları olan antik dönemdeki milletlerin Tanrı' ya nasıl baktıklarını, zihinlerinde nasıl bir tanrı tasavvuru oluşturduklarını özlü bir şekilde ifade etmeye çalıştık.

Antik Yakın Doğu toplumlarındaki Tanrı fikriyatı günümüz tevhid inancından epey farklılık arz etmekedir. Antik dönemdeki milletlerin tanrı mefhumlarının farklı olması ve insanların tanrılarını antropomorfik öğe olarak nitelendirmesi, bu konuda çalışma yapan bizim gibi araştırmacıları kendisine çekmiştir. Fakat sizlere sunduğumuz konu hakkında çok detaylı bir incelemenin yapılmadığını önceki pasajlarımızda arz etmiş idik. Sizlere sunduğumuz bu araştırmamızda Daha çok antik dönemle ilgili olan birinci elden kaynaklara değinmemiz çalışmamızda zikrettiğimiz hususların anlaşılırlığını kolaylaştırmıştır.

Sümerlerde Tanrı'ya çok büyük önem atfedilmektedir. Sümerler bulundukları yerlere mabedler inşa etmişler ve buradaki yapılarda tanrılara hürmetlerini kurbanlar arz ederek ve birtakım sunular gerçekleştirerek göstermişlerdir. Sümerlere ait metinleri incelediğimizde bu metinlerde tanrılar tac giyen, devlet idare eden, kendi aralarında mücadeleler veren birer kral

\footnotetext{
12 Ölülerin Koruyucu Tanrısı. Daha detaylı bilgi için bkz. (The legend of osiris, 2007).
} 
gibidirler. Sümerler ile benzer mahiyette olan Akatların tanrı düşüncesi de doğal olarak pek farklı olmayacaktır. Zira Akatlara ait incelediğimiz metinler Sümer kökenlidir.

Babillilerin tanrı düşüncesi de Sümer ve Akatlardan faklı değildir. Çünkü Babilliler ve Hititliler de Sümer ve Akatlar gibi tanrılarına ibadet için mabedler inşa etmişler, hürmet için ise bir takım sunular gerçekleştirmişlerdir. $\mathrm{Bu}$ sunular, tanrıların sevigisini kazanmak ve tanrılar nezdinde itibar görmek için yapılmıştır. Yine Babillilerde tanrılar arası bir mücadele söz konusudur. Burada da tanrılar insan-tanrı olarak insanların zihinlerinde yer edinmişlerdir. Hitit metinlerinde tanrılar arası gerçekleşen mücadelede yeryüzünde olmayan bir mekandan bahsedilir. Bu yer, tanrıların bulunduğu özel bir yerdir. Mısırlılarda da hiç şüphesiz tanrılar özel bir öneme haizdir. Mısırlılar tanrılarını bağışlayıcı ve esirgeyici olarak görmüş, bu özellikleri nedeniyle Mısırlılar tanrılarına karşı aşırı hürmet göstermiş ve bu nedenle Firavunlar kendilerini mumyalayarak tanrıları için adamışlardır. Ahiret inançları nedeniyle kendilerini sürekli tanrıya karşı sorumlu hissetmişerdir. Mısırlılarda tanrı diğerlerinden farklı olarak devlet idarecisi gibi algılanmamıştır. Tanrı hem dünya hem de ahiret işleriyle hemhal olan bir özelliktedir. Daha çok tanrı mütealdir.

Genel olarak düşünüldüğünde, antik yakın doğu milletlerinde tanrı yeryüzüyle ilgili düzenin sağlanması hususunda emir ve beyanlar veren, yeri geldiğinde gökteki sarayında evi veya meclisinde kararlar kılan, hüküm veren, bağışlayan, esirgeyen, cezalandıran, kendisine adaklar sunulan, ibadetler edilen, kendi aralarında mücadeleler veren, aşık olan, taht makamında oturup taç giyen, duaları kabul eden, o dönemin insanlarının zihinlerinde canlandırdığı, erkek ya da kadın antropomorfik tiplerdir. Antik Yakın Doğu toplumlarında tanrıların antropomorfik unsurlar içermesi, insanların o dönemin önemli şahsiyetleri ile devlet adamlarını yüceltmesi sonucu ortaya çıkmış olabiliceği gibi, tanrı kavramını zihinlerine tam olarak oturtamamaları nedeniyle tanrılara bir takım insani özellikler nispet etmelerinden de kaynaklanmış olabilir.

\section{KAYNAKÇA}

Bratcher, D. (2006). Enuma Elish: The Mesopatimian/Babylonian Creation Myth. 04 Ocak 2012 tarihinde http://www.crivoice.org/enumaelish.html adresinden erişildi.

Champdor, A. (2006). Mısır'ın Ölüler Kitabı: II. Bab. (S. Tahsuğ, Çev.). İstanbul: Madde ve Ruh Yayınları.

Duralı, Ş. T. (2007). Gılgamış Destanı. İstanbul: Dergah Yayınları.

Eyüpoğlu, İ. Z. (2006). Gılgamış Destanı. İstanbul: Özgür Yayınları.

Güç, A. (1988). Mabed. Diyanet İslam Ansiklopedisi (DİA) ( c.27, s.276-277).

Heidel, A. (1951). The Babylonian Genesis (Tablet VI, 104-113). Chicago: University Chicago Press.

Hoffner, H. A. (1998). Hittite Myths. Atlanta: Scholars Press. 
Hornung, E. (2006). Kadim Mısır Ötedünya Kitapları: piramit metinleri. (Z. A. Yılmazer, Çev.). İstanbul: Kabalcı Yayınevi.

Johns, C. H. W. (1911). Code of Hammurabi. 03 Ocak 2012 tarihinde http://www.sacredtexts.com/ane/ham/ham02.htm adresinden erişildi.

Kutsal Kitap. Yaratılış. 11-1-9.

King, L. W. (1901a). The code of Hammurrabi. 04 Ocak 2012 tarihinde, http://www.sacredtexts.com/ane/ham/ham08.htm adresinden erişildi.

King, L. W. (1902b). Enuma Elish (50-58 satırlar). 04 Ocak 2012 tarihinde , http://www.sacred-texts.com/ane/enuma.htm adresinden erişildi.

Kovacs, M. G.(1989). The Epic of Gilgamesh. Standford: Standford University Press.

Kramer, S. N. (1944c). Sumerian Mythology: a study of spiritual and literary achievement in the third millennium b.c. Philadelphia: American Philosophical Society University of Chicago.

Kramer, S. N. (1961). Sumerian Mythology: enki and sumer: the organization of the earth and its culturel processes. 02 Ocak 2012 tarihinde http://www.sacredtexts.com/ane/sum/sum07.htm\#page 59 adresinden erişildi.

Kramer, S. N. (1961). Sumerian Mythology: myths of kur; inanna's descent to neither world. 02 Ocak 2012 tarihinde http://www.sacred-texts.com/ane/sum/sum08.htm adresinden erişildi.

Kramer, S. N. (1963a). The Sumerians: Their history, culture, and character. USA: University of Chicago.

Kramer, S. N. (1988b). The Temple in the Sumerian Literature. M. V. Fox (ed), In temple in society (ss.1-16). USA: University of Chicago.

Pyramid texts, utterances 485. (2007). 05 Ocak 2012 tarihinde http://thepyramidtexts.blogspot.com/2007/09/miscellaneous-group-utterances-453-486.html adresinden erişildi.

Roth, M. T. (1997). Low Collections from Mesopotamia and Asia Minor. Atlanta: Scholars Press.

The Book of the Dead. (2007). 05 Ocak 2012 tarihinde http://abookofthedead.blogspot.com/ adresinden erişildi.

The Building of Ningirsu's Temple (gudea, cylinders a and b). (2006). 27 Aralık tarihinde http://etcsl.orinst.ox.ac.uk/cgi-bin/etcsl.cgi?text=t.2.1.7\# adresinden erişildi.

The Legend of Osiris. (2007). 05 Ocak 2012 tarihinde http://abookofthedead.blogspot.com/ adresinden erişildi. 